\title{
Melatonin modulation of presynaptic nicotinic acetylcholine receptors located on short noradrenergic neurons of the rat vas deferens: a pharmacological characterization
}

W.M. Zago and R.P. Markus
Departamento de Fisiologia, Instituto de Biociências, Universidade de São Paulo, São Paulo, SP, Brasil

\section{Correspondence \\ R.P. Markus \\ Departamento de Fisiologia, \\ Instituto de Biociências, USP \\ Rua do Matão, Travessa 14 \\ 05508-900 São Paulo, SP \\ Brasil \\ Fax: + 55-11-818-7612 \\ E-mail: rpmarkus@usp.br \\ Research supported by FAPESP (No. 96/04497-0) and CNPq (No. 52 0909/96-8). W.M. Zago and R.P. M arkus are recipients of a FAPESP fellowship and a CNPq research fellowship, respectively.}

Received O ctober 22, 1998 Accepted May 12, 1999

\section{Abstract}

Melatonin, the pineal hormone produced during the dark phase of the light-dark cycle, modulates neuronal acetylcholine receptors located presynaptically on nerve terminals of the rat vas deferens. Recently we showed the presence of high affinity nicotine-binding sites during the light phase, and low and high affinity binding sites during the dark phase. The appearance of the low affinity binding sites was due to the nocturnal melatonin surge and could be mimicked by exposure to melatonin in vitro. The aim of the present research was to identify the receptor subtypes responsible for the functional response during the light and the dark phase. The rank order of potency of agonists was dimethylphenylpiperazinium $($ DMPP $)=$ cytisine $>$ nicotine $>$ carbachol and DMPP $=$ nicotine $=$ cytisine $>$ carbachol, during the light and dark phase, respectively, due to an increase in apparent affinity for nicotine. Mecamylamine similarly blocked the DMPP response during the light and the dark phase, while the response to nicotine was more efficiently blocked during the light phase. In contrast, methyllycaconitine inhibited the nicotine-induced response only at 21:00 h. Since $\alpha 7$ nicotinic acetylcholine receptors (nAChRs) have low affinity for nicotine in binding assays, we suggest that a mixed population composed of $\alpha 3 \beta 4$ - plus $\alpha 7$-bearing nAChR subtypes is present at night. This plasticity in receptor subtypes is probably driven by melatonin since nicotine-induced contraction in organs from animals sacrificed at 15:00 $\mathrm{h}$ and incubated with melatonin $(100 \mathrm{pg} / \mathrm{ml}, 4 \mathrm{~h})$ is not totally blocked by mecamylamine. Thus melatonin, by acting directly on the short adrenergic neurons that innervate the rat vas deferens, induces the appearance of the low affinity binding site, probably an $\alpha 7 \mathrm{nAChR}$ subtype.
Key words

- Melatonin

- Neuronal nicotinic

acetylcholine receptors

- Mecamylamine

- Methyllycaconitine

- Vas deferens 


\section{Introduction}

Melatonin, the hormone synthesized and released by the pineal gland, plays a role as an internal timer for several circadian phenomena. Circulating levels of melatonin are synchronized by environmental light, with nightly levels being some 20-50 times higher than those reached during the daytime (1). Recently we showed that melatonin modifies neuronal nicotinic acetylcholine receptors (nAChRs) located on the terminals of short noradrenergic neurons which innervate the rat vas deferens (2). Saturation assays indicate a single class of high affinity nicotine-binding sites $\left(\mathrm{K}_{\mathrm{d}}, 16 \mathrm{nM}\right.$; Bmax, 66 $\mathrm{fmol} / \mathrm{mg}$ protein) when animals are sacrificed in the afternoon. Melatonin, although it does not change the properties of high affinity binding sites, induces the appearance of a second population of lower apparent affinity $\left(\mathrm{K}_{\mathrm{d}}, 36.7 \mathrm{nM}\right.$; Bmax, $185.4 \mathrm{fmol} /$ $\mathrm{mg}$ protein). Competition assays $\left(\left[{ }^{3} \mathrm{H}\right](-)-\right.$ nicotine $x(-)$-nicotine) also suggest the presence of only one binding site, when the animals are sacrificed in the afternoon, and confirm the presence of two binding sites when tissues are exposed to the pineal hormone in vivo (animals sacrificed at 21:00 h) or in vitro (animals sacrificed at 15:00 $\mathrm{h}$ and vasa deferentia incubated for $4 \mathrm{~h}$ in $100 \mathrm{pg} /$ $\mathrm{ml}$ melatonin).

Binding data are correlated with functional responses induced by stimulation of nAChRs. Nicotine induces the contraction of the vas deferens by stimulating receptors located on the noradrenergic nerve terminals which release noradrenaline and ATP $(3,4)$. Thus the contraction induced by stimulation of these receptors is an indirect measure of noradrenaline and ATP release. The affinity for nicotine, estimated by recording vas deferens contraction, is significantly higher at night than in the afternoon (2), suggesting that, as observed in nicotine-induced striatum release of dopamine (5), the functional response reflects stimulation of the lower affinity binding site of the receptor (6).

Neither the contraction nor the displacement of $\left[{ }^{3} \mathrm{H}\right](-)$-nicotine binding by dimethylphenylpiperazinium (DMPP) was modified by the time of day of sacrifice (2), suggesting that only some nicotine-binding sites, or receptor subtypes, are modulated by the pineal hormone.

The identification of multiple ligand binding sites on nAChRs has focused attention on the concept that both site-selective and subtype-selective modulations of nAChR function are possible $(6,7)$. The nAChRs are ligand-gated ion channels whose proteins are encoded by different genes. The identification of $10 \mathrm{nAChR}$ subunit genes in rat, chick and human neuronal tissues indicates a multitude of potential combinations, suggesting that many functional subtypes of neuronal nAChR are possible. Of the neuronal genes, seven $(\alpha 2-\alpha 8)$ code for $\alpha$ subunits, and three ( $\beta 2-\beta 4)$ code for $\beta$ subunits (8). Six subunits ( $\alpha 3, \alpha 4, \alpha 5, \alpha 7, \beta 2$ and $\beta 4)$ for $n A C h R s$ have been identified in the peripheral nervous system (9).

Selective pharmacological probes that functionally differentiate amongst subunit combinations are becoming available. In the present study different agonists (DMPP, cytisine, (-)-nicotine and carbachol) and antagonists (mecamylamine and methyllycaconitine (MLA)) were tested in order to further characterize melatonin modulation of nAChRs. The potency ratio and the efficacy of different agonists, as well as the ability of mecamylamine and MLA to antagonize nicotine-induced contraction were evaluated in the prostatic portion of vasa deferentia removed during the afternoon $(15: 00 \mathrm{~h})$ preincubated or not with melatonin, or removed at night $(21: 00 \mathrm{~h})$. The data are discussed in terms of the selectivity of these ligands for different $\mathrm{nAChR}$ subtypes.

\section{Material and Methods}

Experiments were conducted on Wistar 
rats (4 months old) kept on a 12:12 h lightdark cycle (lights on at 6:00 h) in a soundattenuated room. Food and water were available ad libitum.

\section{Isometric contraction records}

For isometric contraction records, rats were sacrificed at $15: 00$ or $21: 00 \mathrm{~h}(3 \mathrm{~h}$ before, or $3 \mathrm{~h}$ after lights off) because we have previously shown that in organs from animals sacrificed every $3 \mathrm{~h}$ the maximal response to acetylcholine is low at $15: 00 \mathrm{~h}$ and 18:00 $\mathrm{h}$ and increases (5-6 times) at 21:00 h, remaining elevated until 12:00 (10). Each vas deferens was cut transversely to remove the central portion $(10 \%$ of the total length). Only the prostatic portion was used in the experiments. The effect of exogenous melatonin was tested in tissues removed at 15:00 h. Nondissected (hypogastric ganglion present) vasa deferentia were incubated with melatonin $(100 \mathrm{pg} / \mathrm{ml}, 4 \mathrm{~h})$ at $30^{\circ} \mathrm{C}$ in physiological saline solution of the following composition: $135.0 \mathrm{mM} \mathrm{NaCl}, 5.0 \mathrm{mM} \mathrm{KCl}, 1.8$ $\mathrm{mM} \mathrm{CaCl} 2,1.0 \mathrm{mM} \mathrm{NaH}{ }_{2} \mathrm{PO}_{4}, 15.0 \mathrm{mM}$ $\mathrm{NaHCO}_{3}, 5.5 \mathrm{mM}$ glucose, bubbled with $95 \% \mathrm{O}_{2}$ and $5 \% \mathrm{CO}_{2}$, $\mathrm{pH}$ 7.6.

To record isometric contractions, tissues were dissected and suspended under an initial load of $0.5 \mathrm{~g}$ at $30^{\circ} \mathrm{C}$. Longitudinal contraction was recorded with an isometric transducer (F-60, Narco Bio-System, Houston, TX, USA), and displayed on a Narco MK-IV Bio-System physiograph. We allowed the preparations to equilibrate for $20 \mathrm{~min}$ before obtaining a noncumulative concentrationresponse curve for nicotine $(30 \mu \mathrm{M}$ to 1 $\mathrm{mM})$, carbachol ( $0.1 \mathrm{mM}$ to $10 \mathrm{mM})$, cytisine $(10 \mu \mathrm{M}$ to $1 \mathrm{mM})$ or DMPP $(10 \mu \mathrm{M}$ to 1 $\mathrm{mM})$. Nicotine and DMPP were also tested in the presence or absence of nicotine antagonists mecamylamine ( $1 \mathrm{nM}$ or $10 \mathrm{nM})$ or MLA $(10 \mathrm{nM}$ or $10 \mu \mathrm{M})$. The nicotine antagonists were incubated for $1 \mathrm{~h}$ before agonist stimulation.

The apparent affinity of the agonists for the nAChRs is reported as $\mathrm{pD}_{2}$ values (negative logarithm of the dose that produces $50 \%$ of the maximal effect) (11).

\section{Drugs and chemicals}

The following drugs were used: $\mathrm{N}$-acetyl5-methoxytryptamine (melatonin), DMPP, (-)-nicotine, carbachol, mecamylamine (Sigma Chemical Co., St. Louis, MO, USA), MLA (Research Biochemicals International, RBI, Natick, MA, USA), and the salts (Quimitra S/A, Rio de Janeiro, RJ, Brazil).

\section{Statistical analysis}

The $\mathrm{pD}_{2}$ values were calculated with the GRAPHPAD program (Intuitive Software for Science, San Diego, CA, USA). Maximal contraction and $\mathrm{pD}_{2}$ values are reported as mean \pm SEM calculated from individual experiments. The differences between the light and dark phase were compared by the Student $t$-test, and the differences among the several agonists during each period were determined by ANOVA and compared by the Newman-Keuls test, with the level of significance set at $5 \%$.

\section{Results}

\section{Potency ratio for agonists}

Noncumulative concentration-response curves for DMPP, cytisine, nicotine and carbachol were obtained in vasa deferentia removed at 15:00 or 21:00 h (Figure 1). Only one agonist was tested in each preparation. It was added stepwise at various concentrations at 60-min intervals in order to avoid nAChR desensitization. The maximal contraction induced by each agonist was not dependent on the time of day (Table 1).

The $\mathrm{pD}_{2}$ values for DMPP, cytisine, and carbachol did not vary with the time of day, while the $\mathrm{pD}_{2}$ value for (-)-nicotine was higher when animals were sacrificed 
at $21: 00 \mathrm{~h}$ than at $15: 00 \mathrm{~h}$, confirming previous results (2) (Figure 1, Table 1). The rank order of potency for agonistic activity was DMPP $=$ cytisine $>$ nicotine $>$ carbachol, and DMPP $=$ nicotine $=$ cytisine $>$ carbachol for animals sacrificed in the afternoon or at night, respectively. The change in $\mathrm{pD}_{2}$ values for (-)-nicotine was probably due to the nocturnal melatonin surge because the affinity for (-)-nicotine was increased in vasa deferentia removed in the afternoon and incubated with melatonin (100 pg/ml, $4 \mathrm{~h})$ (2).

\section{Inhibition of DMPP- and (-)-nicotine-induced responses by mecamylamine}

Mecamylamine, at $10 \mathrm{nM}$, but not at 1 $\mathrm{nM}$, reduced the maximal contraction induced by DMPP by $70 \%$ in vasa deferentia obtained in the afternoon or at night (Figure 2 ). On the other hand, the effect of mecamylamine on (-)-nicotine-induced contraction was dependent on the time of day (Figure 3). In preparations obtained at 15:00 $\mathrm{h}$, mecamylamine at $1 \mathrm{nM}$ did not change the concentration-response curve to (-)-nicotine, while at $10 \mathrm{nM}$ it completely inhibited the (-)-nicotine-induced contraction. At night, $1 \mathrm{nM}$ mecamylamine had no effect on the concentration-effect curve for nicotine, while

Table 1 - Effect of the time of day of sacrifice on the maximal response and $\mathrm{pD}_{2}$ values for carbachol, cytisine, dimethylphenylpiperazinium (DMPP) and nicotine in the prostatic portion of the rat vas deferens.

Rats were sacrificed at 15:00 or 21:00 h. Data are reported as mean \pm SEM for $\mathrm{N}$ animals. $* \mathrm{P}<0.05$ compared to $15: 00 \mathrm{~h}$ (Student t-test).

\begin{tabular}{lcccr}
\hline Agonist & Hour & $\mathrm{pD}_{2}$ & Maximal response $(\mathrm{g})$ & $\mathrm{N}$ \\
\hline Carbachol & $15: 00$ & $3.00 \pm 0.09$ & $1.59 \pm 0.17$ & 6 \\
& $21: 00$ & $2.80 \pm 0.09$ & $1.96 \pm 0.20$ & 5 \\
Cytisine & $15: 00$ & $4.15 \pm 0.07$ & $1.56 \pm 0.07$ & 12 \\
& $21: 00$ & $3.94 \pm 0.06$ & $1.67 \pm 0.08$ & 12 \\
DMPP & $15: 00$ & $4.20 \pm 0.21$ & $2.47 \pm 0.35$ & 6 \\
& $21: 00$ & $4.10 \pm 0.08$ & $2.74 \pm 0.18$ & 6 \\
Nicotine & $15: 00$ & $3.85 \pm 0.12$ & $1.26 \pm 0.15$ & 16 \\
& $21: 00$ & $4.20 \pm 0.07 *$ & $1.58 \pm 0.11$ & 18
\end{tabular}

at $10 \mathrm{nM}$ it reduced the maximal response by only $67 \%$. Thus, mecamylamine inhibition was more effective in vasa deferentia removed in the afternoon (Figure 3).

\section{Inhibition of (-)-nicotine-induced response by MLA}

During the light phase, MLA (10 $\mathrm{nM}$ or $100 \mathrm{nM})$ did not inhibit nicotine-induced contraction (Figure 3). In contrast, in vasa deferentia isolated during the dark phase, MLA at $100 \mathrm{nM}$, but not at $10 \mathrm{nM}$, reduced the maximal response to nicotine by $58 \%$ $(\mathrm{P}<0.05)$.

\section{Direct action of melatonin on vas deferens preparation}

To test whether the difference between the light and dark phase was due to melatonin, vasa deferentia removed at 15:00 $\mathrm{h}$ were incubated with melatonin (100 pg/ml, $4 \mathrm{~h})$. Mecamylamine $(10 \mathrm{nM})$ was not able to completely block (-)-nicotine-induced contraction (Figure 4). Thus the dark-induced decrease in the potency of mecamylamine could be mimicked by in vitro incubation with melatonin.

\section{Discussion}

nAChRs positively modulate the release of noradrenaline and ATP that contract rat vas deferens smooth muscle cells (3). Unlike metabotropic presynaptic receptors that only influence stimulated release, nAChRs can elicit $\mathrm{Ca}^{2+}$-dependent transmitter release under resting conditions in the rat vas deferens (10) and in the central nervous system (8). The nAChRs located in the terminals of noradrenergic neurons that innervate the rat vas deferens are modulated by melatonin. We have shown that nAChRs are relevant for the neurotransmission of preparations removed from the rat at 21:00, but not at 15:00 h (10), since hexamethonium was able 

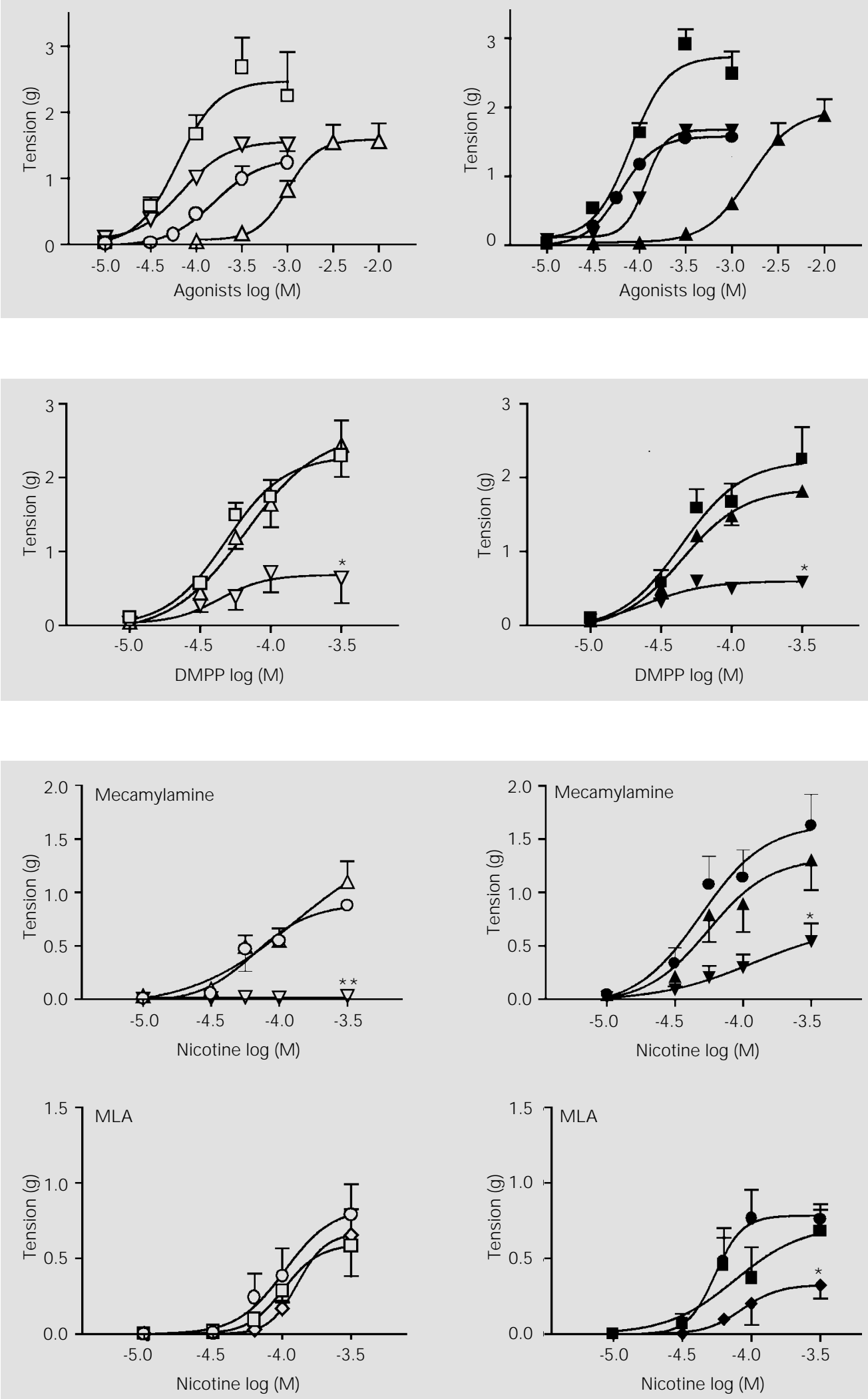

Figure 1 - Noncumulative concentration-effect curves (60-min interval) for dimethylphenylpiperazinium (DMPP) (squares, $\mathrm{N}$ $=6$ ), cytisine (inverted triangles, $\mathrm{N}=12$ ), nicotine (circles, $\mathrm{N}=18$ ) and carbachol (triangles, $\mathrm{N}=6$ ) in the prostatic portion of the rat vas deferens. Animals were killed at 15:00 $\mathrm{h}$ (open symbols) or 21:00 h (closed symbols). Data are reported as mean \pm SEM.

Figure 2 - Mecamylamine inhibition of the noncumulative concentration-effect curve for dimethylphenylpiperazinium (DMPP) in the prostatic portion of the rat vas deferens. Animals were killed at 15:00 $\mathrm{h}$ (open symbols) or 21:00 h (closed symbols). Control in the absence of mecamylamine (squares, $\mathrm{N}=5$ ), $1 \mathrm{nM}$ mecamylamine (triangles, $\mathrm{N}=4), 10 \mathrm{nM}$ mecamylamine (inverted triangles, $\mathrm{N}=5$ ). Data are reported as mean \pm SEM $* \mathrm{P}<0.01$ compared to control (ANOVA + Newman Keuls test).

Figure 3 - Mecamylamine and methyllycaconitine (MLA) inhibition of the noncumulative concentration-effect curve for nicotine in the prostatic portion of the rat vas deferens. Animals were killed at 15:00 $\mathrm{h}$ (open symbols) or 21:00 h (closed symbols). Control in the absence of mecamylamine (circles, $\mathrm{N}=6$ ) or MLA (circles, $N=6$ ). One nanomol mecamylamine (triangles, $\mathrm{N}=6), 10 \mathrm{nM}$ mecamylamine (inverted triangles, $\mathrm{N}=$ 6), $10 \mathrm{nM}$ MLA (squares, $\mathrm{N}=6$ ), and 100 nM MLA (lozenges, $\mathrm{N}=$ 6). Data are reported as mean \pm SEM. Note that $10 \mathrm{nM}$ mecamylamine completely blocked the nicotine-induced contraction in organs obtained at 15:00 h. $* \mathrm{P}<0.01$ and $* * \mathrm{P}<0.001 \mathrm{com}$ pared to control (ANOVA + Newman Keuls test). 
Figure 4 - Effect of endogenous and exogenous melatonin on mecamylamine $(10 \mathrm{nM})$ inhibition of the noncumulative concentration-effect curve for nicotine in the prostatic portion of the rat vas deferens. Animals were killed at 15:00 $\mathrm{h}$ and vasa deferentia were incubated (closed triangles, $\mathrm{N}=8$ ) or not (open triangles, $\mathrm{N}=6$ ) with melatonin, $100 \mathrm{pg} / \mathrm{ml}$, for $4 \mathrm{~h}$ or were killed at 21:00 $\mathrm{h}$ (circles, endogenous melatonin, $\mathrm{N}=9$ ). When animals were killed at 15:00 $\mathrm{h}$ tissues were incubated with mecamylamine (10 nM) throughout the experiments, while tissues from animals sacrificed at 21:00 h were not incubated with mecamylamine. Data are reported as means \pm SEM $* \mathrm{P}<0.001$ compared to control (Student t-test).

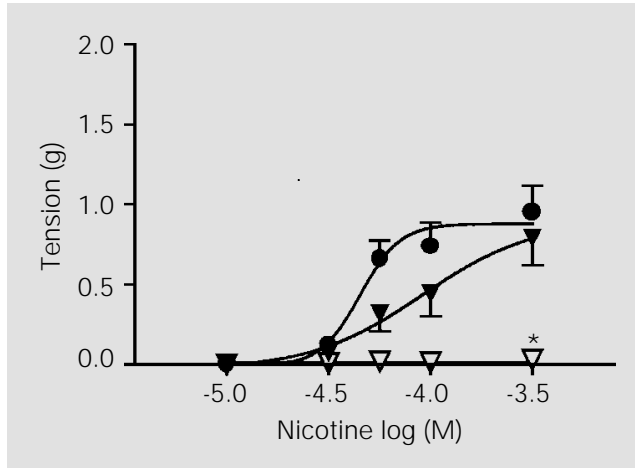

to reduce contraction induced by neuronal transmural stimulation only in the group sacrificed at night. The pineal hormone induced the appearance of a nicotinic low affinity binding site, while a high affinity binding site was present both in the presence and in the absence of the hormone (2). In contrast, the response of smooth muscle cells to both co-transmitters (noradrenaline and ATP) and to depolarizing potassium is not modified by melatonin (10). Thus, at least for this noradrenergic terminal, a change in the modulation of neurotransmission depends on the nocturnal surge of melatonin, which induces nicotinic low affinity binding sites.

In order to determine whether the changes in binding parameters induced by melatonin are due to the appearance of a second receptor subtype, or to a change in the affinity state of a single class of receptors, the potency ratio for agonists and the effect of selective antagonists were compared in tissues exposed or not to the pineal hormone. The efficacy rates for the various agonists tested did not vary with the time of day of the animal sacrifice.

Comparison of the apparent affinity for cytisine and nicotine presents the first indication that melatonin is inducing a second receptor subtype, and not only changing the affinity of a nicotine-binding site. Since the apparent affinity for cytisine was higher than $(15: 00 \mathrm{~h})$ or equal to $(21: 00 \mathrm{~h})$ the apparent affinity for nicotine, the presence of $\alpha 4 \beta 2$ nAChRs was ruled out, because this receptor has a higher affinity for nicotine than for cytisine (12) and cytisine is more selective for receptor subtypes composed of $\beta 4$ units than for those composed of $\beta 2$ subunits (13). Therefore, in tissues obtained during the light phase the high affinity binding sites may be composed of $\alpha \times \beta 4$ subunits. On the other hand, cytisine has been shown to have equal affinity for nicotine in a mixed population of nAChRs composed of $\alpha 3 \beta x+\alpha 7$ receptor subtypes present in IMR32 cells (14). Taking into account that at night the affinity for cytisine did not differ from the affinity for nicotine, it is possible that a mixed population $(\alpha 3 \beta x+\alpha 7)$ is present during the dark phase. Therefore, the comparison of the apparent affinities for nicotine and cytisine and the presence of one binding site in the afternoon and two binding sites at night, taken together, led to the hypothesis that the $\alpha 3 \beta 4$ subtype and $\alpha 3 \beta 4+\alpha 7$ subtypes constitute the nAChR population present in the afternoon and at night, respectively.

Receptors composed of $\alpha 7$ subunits are known to present low affinity for $\left[{ }^{3} \mathrm{H}\right]-(-)-$ nicotine in binding studies, but a high efficacy for (-)-nicotine in single channel conductance studies $(15,16)$. On the other hand, these receptors exhibit low efficacy for DMPP and carbachol $(17,18)$. Thus, an increase in the number of nAChRs composed of $\alpha 7$ subunits (low affinity binding site) without changing the number of $\alpha 3 \beta 4$ subtype (high affinity binding site) could explain the increase in apparent affinity for nicotine without changing the affinity for DMPP, carbachol or cytisine.

To further investigate the suggestion that the proportion of receptor subtypes was dependent on the time of day, we tested the effect of the antagonists mecamylamine and MLA. Mecamylamine $(10 \mathrm{nM})$, a potent nAChR inhibitor composed of $\alpha 3 \beta 4$ subunits $(15,19)$, blocked with higher efficiency the nicotine-induced contraction of vasa deferentia isolated in the afternoon when compared to those isolated at night. On the other 
hand, MLA, which is a selective antagonist of the $\alpha 7$ receptor subtype (6), only inhibited the concentration-response curves for nicotine when the vasa deferentia were obtained during the dark phase. Thus, these results support the view that in the afternoon there is only one subtype of $\mathrm{nAChR}(\alpha 3 \beta 4)$, while at night a second subtype $(\alpha 7)$ also contributes to the nicotine-induced response. Moreover, if an agonist only acts through the $\alpha 3 \beta 4$ nAChR subtype, mecamylamine should be equipotent in both conditions. In fact, inhibition of DMPP-induced contraction by mecamylamine was not dependent on the time of day of sacrifice.

The last question that should be discussed is whether the changes in nAChR subtypes observed at night are due to the nocturnal surge of melatonin released by the pineal gland. Previous data have shown that the incubation of vasa deferentia removed in the afternoon with melatonin $(100 \mathrm{pg} / \mathrm{ml}, 4 \mathrm{~h})$ increases the contraction induced by acetylcholine (10) and induces the appearance of low-affinity binding sites (2). Furthermore, it was demonstrated that the effect of melatonin depends on the presence of the hypogastric ganglion and the duration of incubation (20). In this paper we show that when vasa deferentia were isolated at 15:00 $\mathrm{h}$ and the organs were incubated with melatonin $(100 \mathrm{pg} / \mathrm{ml}, 4 \mathrm{~h})$ the apparent affinity for nicotine increased, while the inhibitory effect of mecamylamine decreased. Both the apparent affinity for nicotine and the inhibitory effect of mecamylamine were significantly different from those of control organs that were not incubated with melatonin. Therefore, the data obtained with nicotine and mecamylamine support the view that melatonin acts directly on the neurons that innervate the vas deferens, and that melatonin is the hormone responsible for the differences observed between the light and the dark phase. This effect is probably dependent on neuronal protein synthesis since it has been shown that melatonin-related changes in acetylcholine-induced response are only observed when the hypogastric ganglion is not removed, and is blocked by cycloheximide (20).

In conclusion, the present data and previous ones $(2,10,20)$ show that the nAChRs located in the nerve terminals of short noradrenergic neurons that innervate the prostatic portion of the rat vas deferens are composed of at least two different subtypes. During the light phase only one subtype, probably $\alpha 3 \beta 4$, is present and at night, due to nocturnal secretion of melatonin by the pineal gland, a second subtype, probably $\alpha$, is expressed.

\section{Acknowledgments}

The technical assistance of Débora Aparecida de Moura is gratefully acknowledged.

\section{References}

1. Reiter RJ (1991). Pineal melatonin, cell biology of its synthesis and of its physiological interactions. Endocrine Reviews, 12: 151-180.

2. Markus RP, Zago WM \& Carneiro RCG (1996). Melatonin modulation of presynaptic nicotinic acetylcholine receptors in the rat vas deferens. J ournal of Pharmacology and Experimental Therapeutics, 279: 18-22.

3. Carneiro RCG \& Markus RP (1990). Presynaptic nicotinic receptors involved in release of noradrenaline and ATP from prostatic portion of rat vas deferens. J ournal of Pharmacology and Experimental Therapeutics, 255: 95-100.

4. von Kügelgen I \& Starke K (1991). Release of noradrenaline and ATP by electrical stimulation and nicotine in guinea-pig vas deferens. Naunyn-Schmiedeberg's Archives of Pharmacology, 344: 419-429.

5. Rapier C, Lunt GG \& Wonnacott S (1990). Nicotinic modulation of $\left[{ }^{3} \mathrm{H}\right]$ dopamine release from striatal synaptosomes: pharmacological characterization. J ournal of Neurochemistry, 54: 937-945.
6. Brioni JD, Decker MW, Sullivan JP \& Arneric SP (1997). The pharmacology of (-)-nicotine and novel cholinergic channel modulators. Advances in Pharmacology, 37: 153-214.

7. McGehee DS \& Role LW (1995). Physiological diversity of nicotinic acetylcholine receptors expressed by vertebrate neurons. Annual Review of Physiology, 57: 521-546.

8. Wonnacott S (1997). Presynaptic nicotinic ACh receptors. Trends in Neurosciences, 20: 92-98. 
9. Rust G, Burgunder J M, Lauterburg TE \& Cachelin AB (1994). Expression of neuronal nicotinic acetylcholine receptor subunit genes in the rat autonomic nervous system. European J ournal of Neuroscience, 6: 478-485.

10. Carneiro RCG, Cipolla-Neto J \& Markus RP (1991). Diurnal variation of the rat vas deferens contraction induced by stimulation of presynaptic nicotinic receptors and pineal function. J ournal of Pharmacology and Experimental Therapeutics, 259: 614619.

11. van Rossum J M (1963). Cumulative doseresponse curves. II. Technique for the making of dose-response curves in isolated organs and the evaluation of drug parameters. Archives Internationales de Pharmacodynamie, 143: 299-330.

12. Vizi ES, Sershen H, Balla A, Mike Á, Windisch K, J urányi ZS \& Lajtha A (1995). Neurochemical evidence of heterogeneity of presynaptic and somatodendritic nicotinic acetylcholine receptors. Annals of the New York Academy of Sciences, 757: 85-99.

13. Papke RL \& Heinemann SF (1993). Partial agonist properties of cytisine on neuronal nicotinic receptors containing the $\$ 2$ subunit. Molecular Pharmacology, 45: 142149.

14. Decker MW, Brioni J D, Bannon AW \& Arneric AP (1995). Diversity of neuronal nicotinic acetylcholine receptors: Lessons from behavior and implications for CNS therapeutics. Life Sciences, 56: 545-570.

15. Albuquerque EX, Pereira EFR, Castro NG, Alkondon M, Reinhard S, Schöder H \& Maelicke A (1995). Nicotinic receptor function in the mammalian central nervous system. Annals of the New York Academy of Sciences, 757: 48-72.

16. Lindstrom J M (1994). Nicotine acetylcholine receptors. In: North A (Editor), Ligandand Voltage-Gated Ion Channels. CRC Handbook of Receptors. CRC Press Inc.,
Florida, 153-176.

17. Bertrand $D$, Bertrand $S \&$ Ballivet $M$ (1992). Pharmacological properties of the homomeric $\alpha 7$ receptor. Neuroscience Letters, 146: 87-90.

18. Gerzanich V, Anand R \& Lindstrom J (1994). Homomers of $\alpha 8$ and $\alpha 7$ subunits of nicotinic receptors exhibit similar channel but contrasting binding site properties. Molecular Pharmacology, 45: 212220.

19. Wong ET, Holstad SG, Mennerick SJ, Hong SE, Zorumski CF \& Isenberg KE (1995). Pharmacological and physiological properties of a putative ganglionic nicotinic receptor $\alpha 3 ß 4$, expressed in transfected eucaryotic cells. Molecular Brain Research, 28: 101-109.

20. Carneiro RCG, Toffoleto O, Cipolla-Neto J $\&$ Markus RP (1994). Modulation of sympathetic neurotransmission by melatonin. European J ournal of Pharmacology, 257: 73-77. 